\title{
ATUALIZAÇÃO CULTURAL E LONGEVIDADE: A PREDOMINÂNCIA DO GÊNERO FEMININO EM ESPAÇOS DE EDUCAÇÃO CONTINUADA: FACULDADE DA TERCEIRA IDADE UNIVAP - EM TEMPOS DE PANDEMIA
}

\section{CULTURAL UPDATE AND LONGEVITY: THE PREDOMINANCE OF THE FEMALE GENDER IN CONTINUING EDUCATION SPACES: SENIOR CITIZENS COLLEGE UNIVAP - IN TIMES OF PANDEMIC}

Débora Wilza de Oliveira Guedes ${ }^{1}$ Alessandra dos Reis Santos ${ }^{2}$ Nayara Benedita Maria de Oliveira ${ }^{3}$

Resumo: Diante do desenvolvimento e dinamicidade societária, e em consonância com os avanços tecnológicos, o envelhecimento humano se caracteriza como um processo de múltiplas transformações: biológicas, psicológicas, sociais e transdisciplinares. Este artigo tem como objetivo analisar o perfil socioeconômico das pessoas idosas que frequentam a Faculdade da Terceira Idade da Universidade do Vale do Paraíba (UNIVAP), localizada no município de São José dos Campos, no estado de São Paulo, demonstrando a predominância do gênero feminino em espaços de educação continuada, a fim de investigar os fatores da longevidade associados à essas mulheres; tendo como metodologia a observação participativa neste meio social através da supervisão de campo e estágio em Serviço Social, junto à pesquisas de abordagem qualitativa e quantitativa acerca da questão. Logo, a temática central do presente artigo é analisar os dados evidenciados no perfil socioeconômico das pessoas idosas que frequentam a Faculdade da Terceira Idade, dados estes elaborados e estudados pelo Serviço Social da Faculdade da Terceira Idade UNIVAP, e os possíveis fatores associados ao aumento da longevidade.

Palavras-chave: Longevidade. Gênero. Educação Continuada. Feminização. Redes Sociais.

Abstract: In the face of dynamics and societal development, and in line with technological advances, human aging is characterized as a process of multiple transformations: biological, psychological, social and transdisciplinary. This article aims to analyze the socioeconomic profile of the elderly people attending the Senior Citizens College at the University of Vale do Paraiba (Univap), located in the city of São José dos Campos, in São Paulo state, demonstrating the predominance of the female gender in spaces of continuing education in order to investigate the factors of longevity associated with these women; having as methodology the participative observation in this social environment through the fieldwork and internship in Social Service, together with qualitative and quantitative researches they approach on the topic. Therefore, the central theme of this article is to analyze the data evidenced in the socioeconomic profile of the elderly people who attend the Senior Citizens College, these data that were elaborated and studied by the Social Service Senior Citizens

\footnotetext{
${ }^{1}$ Doutora em Planejamento Urbano e Regional pela Universidade do Vale do Paraíba, E-mail: deborawo@univap.br.

$\frac{2}{2}$ Graduada em Serviço Social pela Universidade do Vale do Paraíba, E-mail: reisalessandra90@gmail.com.

${ }^{3}$ Graduanda em Serviço Social pela Universidade do Vale do Paraíba, E-mail: nayaranah151@gmail.com.
} 
College "Univap", and the possible factors associated with increased longevity.

Key words: Longevity. Gender. Continuing Education. Feminization. Social Media.

Data de submissão: 28.02 .2021

Data de aprovação: 21.06.2021

Identificação e disponibilidade:

(https://revista.univap.br/index.php/revistaunivap/article/view/2593, http://dx.doi.org/10.18066/revistaunivap.v27i55.2593).

\section{INTRODUÇÃO}

A elaboração deste artigo partiu do pressuposto do aumento da longevidade humana no Brasil e no mundo, o qual está fortemente relacionado com os avanços da tecnologia equivalentes, especialmente, à saúde, que diminuíram as taxas de mortalidade de modo geral. Diante deste cenário de envelhecimento populacional é necessário compreender os múltiplos significados e formas que este fenômeno carrega e aparece no campo social.

Nesse sentido, o presente artigo toma como ponto de partida os espaços de educação informal para pessoas idosas, considerando que com o aumento da expectativa de vida há a necessidade de atualização cultural, como possibilidades de entretenimento e de ampliação de saberes e do convívio social para este segmento populacional.

No entanto, ao observar o envelhecimento sob uma perspectiva biopsicossocial, é notável que há diferentes tipos de velhice na realidade brasileira. Segundo Andrews (2016 apud MADEIRA; GOMES, 2018), e considerando a existência de um recorte racial, o Brasil, mesmo caracterizado como um país pluriétnico, não conseguiu evitar a permanência de grandes disparidades raciais na renda, em inserção qualificada no mercado de trabalho, educação, saúde, expectativa de vida, dentre outros indicadores. Assim, se usou como referência a Faculdade da Terceira Idade (FTI), um reconhecido Projeto de Extensão desenvolvido pela coordenação do curso de Serviço Social da Faculdade de Ciências da Universidade do Vale do Paraíba do município de São José dos Campos, interior do Estado de São Paulo; a qual oferece às pessoas idosas aulas e oficinas de atividades culturais, promovendo a integração idosocomunidade, além do desenvolvimento de projetos intergeracionais.

Ademais, haja vista que a universidade é um importante espaço de produção e disseminação de conhecimentos, a extensão universitária da Faculdade da Terceira Idade é vista como uma das funções sociais da instituição, levando ao público externo informações, por meio do ensino e da pesquisa, e ao mesmo tempo, realizando a articulação instituição de ensino e comunidade - com vistas ao desenvolvimento e participação social e à troca de saberes. Dessa maneira, analisar e compreender o público que frequenta a $\mathrm{FTI}$ é fundamental para um bom desenvolvimento de ações em conformidade com as demandas que são requisitadas por esta comunidade.

Contudo, devido a pandemia instaurada em março de 2020 no país, novas estratégias foram lançadas pela Faculdade da Terceira Idade para que o conhecimento em modalidade de educação continuada chegasse ao segmento populacional atendido no espaço, já que por este motivo, as aulas e oficinas desenvolvidas na FTI foram suspensas. Nessa perspectiva, foram utilizados os recursos de redes sociais para a produção e disseminação de conhecimento, através 
de publicações sobre a Faculdade da Terceira Idade, atualização de notícias e conhecimento de mundo de modo geral; além de eventos abertos - lives, via Facebook e Youtube - com equipe multiprofissional, realizando debates sobre o momento atual, qualidade de vida e envelhecimento. Sendo assim, e tendo em vista o público atendido pelo local, o artigo evidenciará as características deste e a procura pela atualização cultural em meios de educação continuada; uma vez que a maior adesão às atividades desenvolvidas - em espaço presencial e virtual - é realizada por mulheres, fato este que direciona à reflexão acerca da sobreposição da longevidade feminina à masculina.

Logo, o artigo tem como objetivo analisar o perfil socioeconômico das pessoas idosas que frequentam a Faculdade da Terceira Idade UNIVAP, em sua maioria mulheres, a fim de evidenciar quem são, segundo as condições analisadas, e quais os possíveis fatores à estas associadas acerca da longevidade.

Portanto, a metodologia consiste na análise do documento socioeconômico desenvolvido pela Secretaria Administrativa da FTI, além de pesquisa exploratória e descritiva acerca dos temas envelhecimento humano, longevidade e educação continuada e informal, com levantamento de dados de abordagem qualitativa e quantitativa, pois, para Gil (2008), os tipos de pesquisa se fundamentam em explicitar o problema, o qual proporciona maior familiaridade a partir da descrição das características de determinadas populações ou fenômenos e inclui observação participante das autoras, no cotidiano de prática e supervisão de estágio.

\section{LONGEVIDADE E VELHICE}

Longevidade é caracterizada pela qualidade de um indivíduo ou grupo de viver mais, ou seja, pela duração de vida - como um sinônimo de expectativa de vida longa. Por isso, a palavra longevidade está intrinsicamente ligada ao envelhecimento humano, o qual é estudado por diversas áreas do conhecimento multidisciplinar.

Entretanto, há um problema acerca da velhice no campo social, o qual é apontado por Beauvoir, em A Velhice: Realidade Incômoda (1970). Em que para a autora o problema da velhice se encontra no fato do indivíduo não se enxergar nesta condição - o de tornar-se velho. Segundo Anita Liberalesso Neri (2006 apud IMPERATORI, 2007), tal situação é dada pela chamada medicalização da velhice que se trata do poder concentrado na medicina para explicar o processo de envelhecimento -, construída no contexto histórico-social da sociedade, sendo ressaltado que:

1 - supergeneralização: crença em que todos os idosos são doentes ou que
a velhice é uma doença; 2 - supersimplificação: crença em que o
envelhecimento ocorre da mesma forma em todas as pessoas e tem os
mesmos resultados 3 - reducionismo: crença em que o modelo biomédico
consegue explicar de forma completa o envelhecimento; 4 - pseudocientífica:
crença em que todas as descobertas médicas e tecnológicas têm base
científica; 5 - ilusão sobre a imediaticidade da aplicação da pesquisa básica:
crença de que os produtos de pesquisa e tecnologia direcionados para a
velhice estão ao alcance de todos (NERI, 2006 apud IMPERATORI, 2007, p.
22-23).

Assim, para que a velhice assuma o papel que lhe é, de fato, imposto, Simone de Beauvoir (1970) propõe que cada indivíduo social se reconheça na pessoa velha, a fim de aceitar as adversidades da idade final. 
O Estatuto do Idoso (BRASIL, 2003), reconhece como pertencentes a esta categoria, aqueles indivíduos que possuem idade igual ou superior a 60 anos; já em países com um maior índice de desenvolvimento, a idade mínima para ser considerado idoso é de 65 anos, ou seja, a "categoria" idoso se trata de uma construção social, que pode variar de acordo com a cultura, localidade, tempo histórico, entre outros fatores, pois o processo de envelhecimento em si, independe de tais fatores, pois nos acompanha durante toda a vida, desde o nascimento até a finitude de nossos dias, além de ser natural para todos os seres humanos, contudo, cada indivíduo envelhece de maneira singular.

A velhice é uma fase do desenvolvimento humano, e tem suas características próprias, assim como as demais, e se evidencia por aspectos biológicos, psicológicos e sociais, que vão sendo construídos durante a vida dos sujeitos, logo, devemos nos aproximar da velhice com a compressão de seu aspecto biopsicossocial.

(...) portanto, ao conceituar a velhice é necessário considerar o conjunto dos aspectos biológicos, psicológicos e sociais, além das experiências vividas pelo idoso, na sua trajetória pessoal, em especial suas reações frente à realidade que o cerca (GUEDES, 2006, p. 19).

Indivíduo e sociedade possuem uma interação dialética, onde formam e são formados, e por este motivo, a concepção de velhice, e os valores a ela agregados são construídos na sociedade, por isto também o aumento da longevidade significa um desafio social, econômico, político e intergeracional.

O avanço tecnológico é um dos fatores primordiais que contribuem significativamente para o aumento da longevidade, porém muitas vezes, pode se tornar uma barreira no processo de inclusão do sujeito idoso no que se denomina vida moderna, desta maneira, é primordial que Estado, sociedade e família, em consonância com o Estatuto do Idoso (BRASIL, 2003), pensem maneiras e delineiem estratégias para inserção deste grupo societário em redes comunicação digital, conforme preconizado no artigo 21, parágrafo primeiro do Estatuto: " $\S 1^{\circ}$ os cursos especiais para idosos incluirão conteúdo relativo às técnicas de comunicação, computação e demais avanços tecnológicos, para sua integração à vida moderna." (BRASIL, 2003).

Encarar o processo de envelhecimento e acompanhar todas as atualizações do mundo tecnológico é uma tarefa bastante difícil, e pensando nisso é que se justifica o trabalho realizado pela Faculdade da Terceira Idade, tendo em vista que o perfil de alunos/as é caracterizado por estar nessa fase de desenvolvimento humano, e se mostram grandes adeptos do uso das novas tecnologias.

\section{FEMINIZAÇÃO DA VELHICE}

O Brasil, assim como vários outros países, vem apresentando significativo aumento da longevidade de sua população, e por este motivo se faz importante desenvolver estudos acerca do tema, com vistas a entender e se aproximar deste grupo societário, possibilitando a construção coletiva de "um padrão de vida que lhes seja adequado" (MINAYO 2002 apud. FIGUEIREDO et al., 2007, p. 2).

Segundo dados do Instituto Brasileiro de Geografia e Estatística (IBGE), divulgados em 2018 na Pesquisa Nacional por Amostras de Domicílio Contínua (PNAD), a população idosa representava $14,6 \%$ do total no país, sendo $6,4 \%$ homens e $8,2 \%$ mulheres. Fazendo um recorte apenas da porcentagem de idosos, obtemos o 
resultado de que as mulheres representam $56 \%$ dessa população, enquanto os homens $44 \%$, portando se observa um processo de feminização da velhice no país (IBGE, 2018).

Vários estudos demográficos apontam a disparidade entre os gêneros no que concerne ao alcance da fase da velhice, última etapa do desenvolvimento humano: as mulheres alcançam maior longevidade, "constituem a maior parte da população mundial idosa" (FIGUEIREDO et al., 2007, p. 2).

Quando se faz o recorte de gênero em estudos e pesquisas, é possível observar as relações desiguais no âmbito político, econômico e social, transcenderem as diferenças biológicas, e passarem a serem observadas, também, por meio de um olhar histórico, que contempla as construções sociais e culturais acerca do feminino e masculino, além de modelos, ideias, valores e papéis sociais que cada indivíduo "deve" cumprir de acordo com o gênero a qual pertence.

A questão de gênero e desigualdade entre homens e mulheres, assim como o aumento da longevidade, são fatores novos no mundo das pesquisas, e por este motivo não há um grande número de produções científicas que interligam estas duas temáticas; o que se sabe é que há predominância de mulheres com idade igual ou superior a 60 anos, porém, este fenômeno é visto apenas em seu aspecto qualitativo, numa perspectiva estatística.

\begin{abstract}
Neste dinâmico processo de mudança no ciclo vital na estrutura demográfica, econômica, política [...] na maneira de viver e estabelecer relações sociais, pelo menos três mudanças são especialmente relevantes para lançar luz sobre os novos papéis sociais do/a velho/a na atualidade e suas novas formas de sociabilidade: i) mudanças na estrutura etária da população; ii) na socioeconômica; iii) e nos papéis de gêneros (FIGUEIREDO et al., 2007, p. 2).
\end{abstract}

De acordo com Debert (1994), há dois tipos de autores que pensam o envelhecimento feminino de diferentes maneiras. Para alguns, mulheres na fase da velhice são alvos de dupla vulnerabilidade, enquanto na situação de mulher e idosa, para outros. A velhice feminina é vista de maneira mais otimista do que a masculina, uma vez que "a mulher não experimenta uma ruptura, em relação ao trabalho, tão violenta quanto a dos homens na aposentadoria" (DEBERT, 1994, p. 33).

Em uma sociedade com valores capitalistas, onde ocorre a supervalorização da juventude, principalmente masculina, enquanto fase de maior produtividade e consumo, a tendência é que com o advento da aposentadoria, os homens encarem e vivenciem o processo de envelhecimento com baixa autoestima, isto ocorre também por questões como: perda parcial ou total da autonomia (em decorrência da perda de funções vitais, reprodutivas e/ou surgimento de doenças), sensação de perda de poder e liberdade, visto que, as construções históricas e sociais determinam "as relações de força e poder [...] hegemônico, para o masculino tomando para si o espaço público, destinando-se o espaço privado do lar para mulher" (FIGUEIREDO et al., 2007, p. 3).

Em contrapartida, muitas mulheres tendem a encarar o processo de envelhecimento como algo libertador, e isso decorre do sentimento de conquista da própria independência e autonomia, seja econômica ou social. Sabe-se que, em sociedades patriarcais, o ambiente doméstico, espaços privados e cuidados com filhos e netos, são afazeres que se destinam e se associam a figuras femininas, portanto, quando alcançam a fase da velhice, as mulheres tendem a se sentirem "livres" daquelas obrigações que Ihes eram impostas. 
(...) a mulher idosa mostra-se mais adaptada, indo além destas limitações impostas pela idade, conseguindo com resistência e sensibilidade conquistar até a autonomia financeira [...], uma vez que, até, muitas dessas mulheres idosas não tinham dinheiro para comprar objetos, bens e serviços de uso pessoal, dependiam do poder econômico do marido e dos filhos. Além da autonomia financeira, a liberdade parece ser evidente, pois a mulher idosa tem mais tempo disponível para si própria, pelo fato de ter uma redução nas obrigações com os filhos, que, por sua vez, ao se casarem, vão viver em seus lares de forma independente. A presença e a permanência do marido no lar, também dão as mulheres idosas mais segurança e liberdade para participarem de atividades sócio educativas nos espaços de socialização da terceira idade, tais como, universidades, centros de convivência e clubes de terceira idade, estes espaços fornecem informações fundamentais sobre direitos e cidadania (FIGUEIREDO et al., 2007, p. 5).

É possível então observar, durante o processo de envelhecimento, certo rompimento de padrões e valores impostos em relação aos papéis que devem ser desempenhados por cada gênero. Envelhecer é uma experiência homogênea (DEBERT, 1994), e é vivido de maneiras diferentes por cada indivíduo, com fortes influências dos aspectos de gênero, classe, etnia e cultura. Nesse ponto de vista, Motta (1999) entende esses aspectos como inseridos numa dimensão básica da vida social, pois:

Essas dimensões realizam-se no cotidiano e na História e podem ser também
definidas como categorias relacionadas ou da experiência. Expressam
diferenças, oposições, conflitos e/ou alianças e hierarquias provisórias.
Provisórias, porque na dialética da vida os lugares sociais se alternam, as
situações sociais desestruturam-se e reconstróem-se em outros moldes. Do
ponto de vista de cada indivíduo ou grupo, isto significa a múltipla pertinência
de classe, de sexo/gênero, de idade/geração e de raça/etnia, com a formação
de subjetividades ou de identidades correspondentes (MOTTA, 1999, p. 193).

Posto isso, diante dos diferentes modos de envelhecer e que ao conhecer essas categorias, infere-se a existência de relações de poder perpassadas no campo social na convivência entre os indivíduos, como pontua Motta (1999), há hierarquias internas a cada dimensão; tem-se como exemplo a dimensão de gênero: há homens e mulheres - cada um apresentando variações internas à sua condição, de cor, classe etc - no qual se direciona para uma diversidade de experiências de gênero, ou seja, uma multiplicidade de formas do envelhecer e seu estudo.

\section{DEMOGRAFIA DA POPULAÇÃO IDOSA NO BRASIL E EM SÃO JOSÉ DOS CAMPOS/SP}

A longevidade da população aumenta a cada ano no Brasil, pois é indicado pelas Tábuas Completas de Mortalidade, divulgado em 2019 pelo Instituto Brasileiro de Geografia e Estatística (IBGE), que a expectativa de vida dos brasileiros do ano de 2017 para 2018 aumentou em três meses e quatro dias, alcançando 76,3 anos. Ademais, o estudo aponta que já são 30,8 anos a mais que a população se espera viver desde os anos de 1940 (ESTATÍSTICAS SOCIAIS, 2019).

Dessa forma, ainda nestes indicadores é revelado que há uma diferença de longevidade entre homens e mulheres, no qual estas possuem uma maior expectativa 
de vida, com 79,9 anos, enquanto para os homens era de 72,8 anos, em 2018. Este fenômeno que atinge com maior intensidade a população masculina, conforme explica Marcio Minamiguchi, pesquisador do IBGE, é evidenciado por fatores não naturais, e sim por causas externas provenientes da urbanização, os quais inclui homicídios, quedas acidentais e acidentes de trânsito - gerados, especialmente, a partir dos anos 80. Cabe ainda ressaltar, que no ano de 2019 a proporção de mulheres com 80 e mais anos supera a de homens, com cerca de quase $2 \%$ da população de acordo com a Pesquisa Nacional por Amostra de Domicílios Contínua 2012/2019 (IBGE EDUCA, 2019), conforme a pirâmide etária do Brasil:

Figura 1 - Pirâmide etária do Brasil.

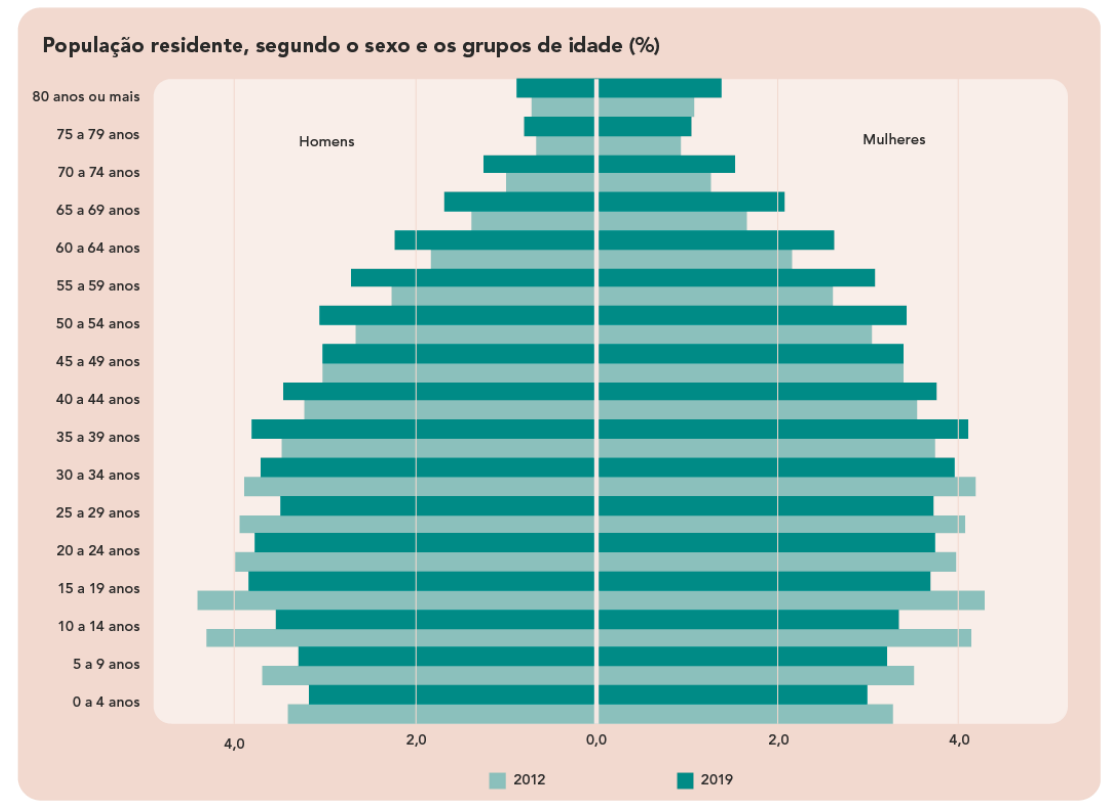

Fonte: IBGE educa (2019).

Segundo dados da Fundação Sistema Estadual de Análise de Dados (SEADE), em 2020, o evidente aumento da longevidade humana no país está relacionado com as melhorias nas condições de vida da população, apesar da permanência das disparidades entre as regiões e as expressivas diferenças de esperança de vida por sexo; em São Paulo por exemplo, a esperança de vida feminina era de 79,4 anos e a masculina, de 73,3 anos em 2019.

Portanto, a pirâmide etária do Brasil revela um gradual envelhecimento da população. De acordo com o SEADE (2017), até 2050, o número de pessoas a partir de 65 anos deverá crescer de modo mais intenso, passando de 7,8\%, em 2010, para $22,7 \%$; fazendo com que tal situação demanda atenção pública frente às necessidades sociais das pessoas idosas.

A cidade de São José dos Campos, é um município de São Paulo localizado no interior do estado. A cidade é conhecida por sua fase senatorial, durante o século XX, devido às suas condições climáticas favoráveis ao tratamento de tuberculose - o qual aumentou a procura pela cidade, esta que por esse motivo inaugurou o Sanatório Vicentina Aranha, em 1924. Todavia, com a industrialização no século XXI, São José dos Campos se destaca com a instalação na cidade da Tecelagem Parahyba; e hoje como um forte espaço de avanços tecnológicos, com as instalações do Departamento de Ciência e Tecnologia Aeroespacial (DCTA), do Instituto Tecnológico de Aeronáutica (ITA) e do Instituto de Pesquisas Espaciais (INPE). Ressalta-se ainda, a boa 
localização da cidade por meio da Rodovia Presidente Dutra, possibilitando o fácil acesso à capital de São Paulo, litoral norte ao sul do estado de Minas Gerais. De acordo com a figura 2, a localização do município:

Segundo dados da notícia "Vive-se mais e melhor", da Fundação Sistema Estadual de Análise de Dados (SEADE, 2020), em 2020, o evidente aumento da longevidade humana no país está relacionado com as melhorias nas condições de vida da população, apesar da permanência das disparidades entre as regiões e as expressivas diferenças de esperança de vida por sexo; em São Paulo por exemplo, a esperança de vida feminina era de 79,4 anos e a masculina, de 73,3 anos em 2019.

Portanto, a pirâmide etária do Brasil revela um gradual envelhecimento da população. De acordo com o levantamento "Em 2050, a população idosa irá triplicar no Estado de São Paulo" (SEADE, 2017), até 2050, o número de pessoas a partir de 65 anos deverá crescer de modo mais intenso, passando de 7,8\%, em 2010, para $22,7 \%$; fazendo com que tal situação demanda atenção pública frente às necessidades sociais das pessoas idosas.

A cidade de São José dos Campos, é um município de São Paulo localizado no interior do estado. Segundo informações de São José dos Campos (2016), a cidade é conhecida por sua fase senatorial, durante o século $X X$, devido às suas condições climáticas favoráveis ao tratamento de tuberculose - o qual aumentou a procura pela cidade, esta que por esse motivo inaugurou o Sanatório Vicentina Aranha, em 1924. Todavia, com a industrialização no século XXI, São José dos Campos se destaca com a instalação na cidade da Tecelagem Parahyba; e hoje como um forte espaço de avanços tecnológicos, com as instalações do Departamento de Ciência e Tecnologia Aeroespacial (DCTA), do Instituto Tecnológico de Aeronáutica (ITA) e do Instituto de Pesquisas Espaciais (INPE). Ressalta-se ainda, a boa localização da cidade por meio da Rodovia Presidente Dutra, possibilitando o fácil acesso à capital de São Paulo, litoral norte ao sul do estado de Minas Gerais. De acordo com a figura 2, a localização do município:

Figura 2 - Localização do município de São José dos Campos.

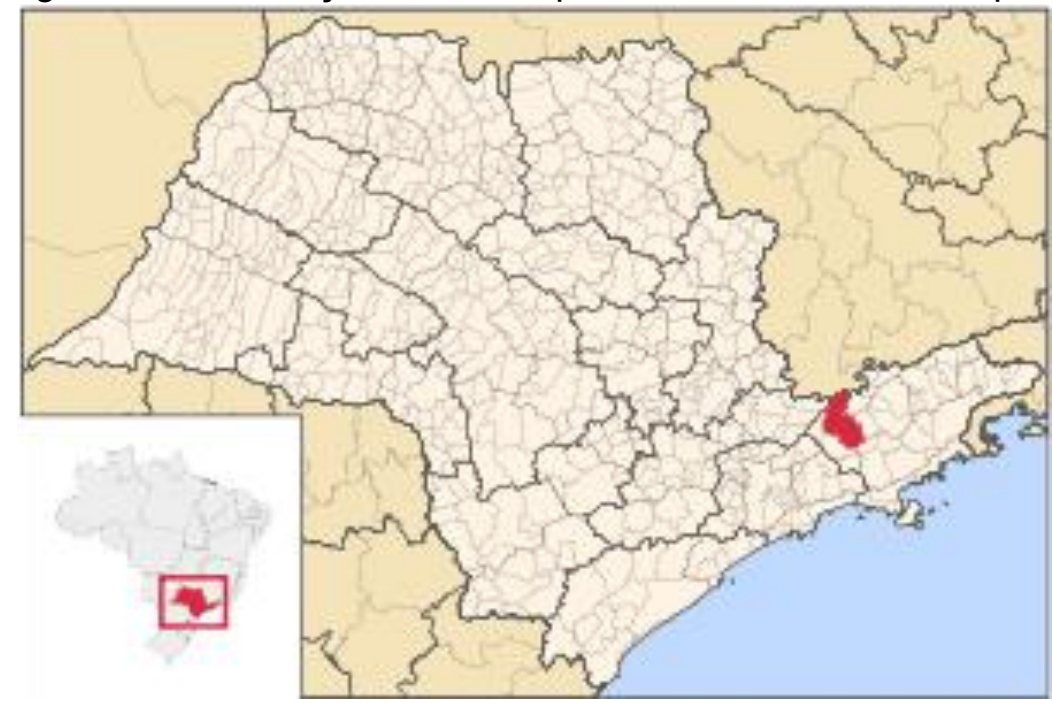

Fonte: Google Imagens (2021).

Nesse sentido, em São José dos Campos, os dados acerca do envelhecimento populacional seguem em consonância com os dados nacionais. De acordo com 
informações do Atlas Brasil (2017), a taxa de envelhecimento no município aumentou para $6,22 \%$ em 2010; além de que estimativas de 2017 apontam que população é composta em sua maioria por mulheres $(51,01 \%)$. Logo, tem-se que a pirâmide etária de São José dos Campos reflete no aumento da longevidade, essencialmente do sexo feminino, sendo que no ano de 2010: a população entre 65 e 69 anos já demonstrava diferenças na porcentagem em razão dos sexos, 7,78 para mulheres e para homens, 6,95 .

Destaca-se que para a população de 80 e mais anos esse número é ainda maior: 4,82 para mulheres e 2,86 para homens. Assim, neste mesmo ano, a esperança de vida ao nascer é certamente maior para as mulheres $(79,69)$ do que para os homens $(72,82)$, no mesmo estudo indicador. À vista disso, considera-se a melhoria no campo da saúde - medicamentos, vacinas e controles de doenças -, saneamento básico e condições de bem-estar suscetíveis e colaboradoras dos diferentes processos de envelhecimento populacional; e cabe refletir acerca dos espaços e serviços destinados às pessoas idosas, que atendem suas demandas com relação à educação e lazer, dentro da conjuntura evidenciada em São José dos Campos.

\section{FACULDADE DA TERCEIRA IDADE UNIVAP}

As instituições de ensino superior (IES) comunitárias são aquelas que não possuem finalidades lucrativas, reinvestem todos os resultados na própria atividade educacional. As universidades comunitárias são mantidas pela sociedade civil e contribuem para o desenvolvimento do país através da oferta de educação de qualidade.

A prestação de serviços sociais de utilidade pública é imprescindível à IES que pretende se tornar uma comunitária. Estes serviços podem ser caracterizados como responsabilidade social, filantropia, voluntariado ou mais comumente, projetos de extensão.

A Universidade do Vale do Paraíba (UNIVAP) como uma universidade, deve seguir a prerrogativa disposta no artigo 207 da Constituição Federal (1988), que afirma: "as universidades gozam de autonomia didático-científica, administrativa e de gestão financeira e patrimonial, e obedecerão ao princípio de indissociabilidade entre ensino, pesquisa e extensão" (BRASIL, 1988, grifo nosso).

Dessa maneira, reconhecida em 1992 pelo Ministério da Educação (MEC), a Univap é dada como uma instituição comunitária sem fins lucrativos, de ensino, pesquisa e extensão. Portanto, são de iniciativa e mantidas pela sociedade civil e contribuem para o desenvolvimento nacional ofertando educação de boa qualidade.

Desse modo, segundo o Resumo Interno do Projeto da Faculdade da Terceira Idade Univap (2021), esta é um programa institucional em nível de extensão implantado na Univap desde agosto de 1991, e possui como principais objetivos permitir o acesso à educação continuada às pessoas com idade acima de 45 anos, sobretudo às pessoas idosas, assim como oferecer condições para integração da pessoa idosa na comunidade.

É um programa de cunho eminentemente social, que tem como ponto de partida o reconhecimento do potencial de contribuição das pessoas da terceira idade para a sociedade. Essas pessoas, na maioria dos casos, não tiveram oportunidades de estudar; outras, na condição de doença ou aposentadas, encontram dificuldades para retomar seu espaço social.

Além disso, a Faculdade da Terceira Idade é um importante Campo de Estágio Profissional, Estudos e Pesquisas para os alunos da Univap, município de São José 
dos Campos e região do Vale do Paraíba.

Dessa maneira, a FTI congrega o Curso de Extensão e Atualização Cultural (CEAC) e o Centro de Estudos Avançados para Terceira Idade (CEATI). Sendo que CEAC é ministrado em dois semestres, com duração de um ano letivo; e em continuidade a esse curso os (as) alunos (as) que completarem os dois semestres se habilitam a frequentar o CEATI.

O Centro de Estudos Avançados para a Terceira Idade (CEATI) é organizado em módulos semestrais com temáticas e assuntos que são variados e recorrentemente atualizados, sendo que o aluno pode inscrever-se e cursar até dois módulos por semestre.

Logo, para os alunos e alunas devidamente inscritos e frequentes no CEAC ou no CEATI são ofertadas atividades de expressão sensível, arte e cultura, optativas, no formato de oficinas optativas/eletivas. Nestas atividades os alunos e alunas do CEAC e CEATI têm a oportunidade de socialização e integração durante o desenvolvimento da oficina.

\subsection{FACULDADE DA TERCEIRA IDADE NO CONTEXTO DE PANDEMIA}

No primeiro semestre de 2020, o funcionamento das aulas, oficinas, eventos e atendimento aos alunos/as, professores/as e público em geral presenciais, ocorreram apenas nos meses de fevereiro e março. No dia 12 de março as atividades presenciais foram suspensas por conta da pandemia do coronavírus (Covid-19), em seguida, no dia 23 de março, em razão da conjuntura posta, referente à saúde no Brasil e no mundo, especialmente sobre os cuidados peculiares e responsabilidades que devem ser dirigidas às pessoas idosas, e em consonância com as orientações do Ministério da Saúde e Governo do Estado de São Paulo, as atividades da FTI foram canceladas.

Por meio das reuniões, e de acordo com o Plano de Estágio em Serviço Social na Faculdade da Terceira Idade UNIVAP, as estagiárias iniciaram um processo de ligações para os alunos e alunas da FTI, com o objetivo de realizar um monitoramento social - remoto - e fazer uma reflexão com o (a) aluno (a), evidenciando fatos informativos, de maneira que o (a) mesmo (a) compreenda a importância do cuidado com a saúde. Logo, através dos instrumentos da fala e escuta diferenciada foi possível coletar demandas que, na maioria das vezes, não são próximas e reconhecidas no cotidiano da normalidade das atividades presenciais da FTI.

Durante a realização do monitoramento social, vários dos (as) alunos (as) relataram as mídias sociais como uma ferramenta de grande ajuda neste determinado momento, pois, há a possibilidade se aproximar dos entes de uma maneira segura e rápida; disseram também que as aulas de crossmedia, ofertadas no segundo semestre de 2019 , foram essenciais para que pudessem utilizar da melhor maneira os meios tecnológicos e informacionais de comunicação.

A metodologia utilizada durante o segundo semestre do ano de 2020 na Faculdade da Terceira Idade UNIVAP deu-se como uma metodologia participativa de toda equipe do Projeto, de modo ativo e coletivo. E, a partir das ligações realizadas e das interações nas redes sociais com os alunos e alunas, foi possível elaborar atividades remotas seguindo suas objeções, a exemplo o mês de outubro, em comemoração ao Dia Internacional da pessoa idosa, no qual foi realizado um evento na plataforma do Youtube, em que houve um retorno positivo e grande aderência dos (as) alunos (as) do Projeto.

Ademais, foi feito o acompanhamento do grupo de estudos, iniciado no ano de 2019, sendo majoritariamente composto por mulheres, e como uma demanda 
emergente dos (as) próprios (as) alunos (as) que integram o Projeto, com vistas a discutir temas pertinentes na atualidade, bem como realizar pesquisas e participar de congressos dentro da própria universidade ${ }^{4}$. O grupo continuou com seus encontros de maneira remota durante o período de quarentena, e em reunião com a coordenação, relataram que não desejam se desvincular da FTI, mas que visam manter sua autonomia enquanto grupo. Dentre a participação em eventos, os (as) integrantes fizeram uma participação especial, junto ao curso de Serviço Social, no $18^{\circ}$ Congresso Saúde e Qualidade de Vida do Cone Leste Paulista (Qualivitae), da Univap, recitando um poema em forma de jogral, além de participarem da discussão sobre o processo de envelhecimento.

Portanto, é possível compreender que o papel que a educação desempenha na vida dos idosos que participam da Faculdade da Terceira idade é de extrema importância para estes, que manifestam a grande mudança que o Projeto proporcionou em suas vidas, no âmbito social, educacional e cultural.

\section{PERFIL SOCIOECONOMICO DA FACULDADE DA TERCEIRA IDADE UNIVAP COM ÊNFASE DA QUESTÃO DE GÊNERO}

Diante da realidade social vivenciada no município de São José dos Campos, acerca do aumento gradual do número de pessoas idosas, a Faculdade da Terceira Idade UNIVAP possui anualmente cerca de 270 alunos inscritos em média, com frequência acima de $70 \%$ - valor considerado para a permanência na instituição. Logo, para fins de análise desse segmento populacional mencionado, esta seção evidencia os principais aspectos do perfil socioeconômico coletado pelo curso de Serviço Social da UNIVAP, o qual é responsável pela coordenação do espaço e mediação entre a universidade, idoso e comunidade.

Dessa maneira, os dados a seguir são dos (as) inscritos na FTI durante o segundo semestre do ano de 2019, sendo um total de 268 pessoas em que $90,3 \%$ pertencem ao sexo feminino, conforme o quadro 1 :

Quadro 1 - Total de inscritos na FTI por sexo.

\begin{tabular}{|c|c|c|}
\hline \multicolumn{3}{|c|}{ SEXO } \\
\hline Feminino & Masculino & TOTAL \\
\hline 242 & 26 & 268 \\
\hline $90,3 \%$ & $9,7 \%$ & $100 \%$ \\
\hline
\end{tabular}

Fonte: Faculdade da Terceira Idade Univap (2019).

Com relação à idade dos alunos e alunas da $\mathrm{FTI}$, se verifica no quadro 2 uma maior predominância entre 58 e 64 anos, com cerca de 81 pessoas $(30,2 \%)$, em seguida e com pouca diferença, vê-se pessoas idosas de 65 a 71 anos, com uma porcentagem de $29,1 \%$. Ressalta-se que o número de pessoas idosas entre 86 e 92 anos tende a crescer com o passar do tempo, com base nas mudanças da pirâmide etária e o envelhecimento populacional de escala mundial.

\footnotetext{
${ }^{4}$ Alguns alunos do grupo de estudos tiveram suas pesquisas publicadas em Congressos como INIC (Congresso Nacional de Iniciação Científica) e Qualivitae (Congresso de Saúde e Qualidade de Vida do Cone Leste Paulista), nos anos de 2019 e 2020.
} 
Quadro 2 - Nascimento dos inscritos na FTI.

\begin{tabular}{|c|c|c|c|}
\hline \multicolumn{4}{|c|}{ DATA DE NASCIMENTO } \\
\hline Ano de Nasc. & Idade & Alunos & $\%$ \\
\hline $1927-1933$ & De 86 a 92 anos & 6 & $2,2 \%$ \\
\hline $1934-1940$ & De 79 a 85 anos & 22 & $8,2 \%$ \\
\hline $1941-1947$ & De 72 a 78 anos & 47 & $17,5 \%$ \\
\hline $1948-1954$ & De 65 a 71 anos & 78 & $29,1 \%$ \\
\hline $1955-1961$ & De 58 a 64 anos & 81 & $30,2 \%$ \\
\hline $1962-1968$ & De 51 a 57 anos & 22 & $8,2 \%$ \\
\hline $1969-1974$ & De 45 a 50 & 2 & $0,8 \%$ \\
\hline Não informou & - & 10 & $3,8 \%$ \\
\hline \multicolumn{2}{|c|}{ TOTAL } & 268 & $100 \%$ \\
\hline
\end{tabular}

Fonte: Faculdade da Terceira Idade Univap (2021).

Quanto à condição de moradia, de acordo com o quadro 3 a maioria dos (as) inscritos afirmam morar sozinhos (as) $(38,4 \%)$, evidenciando um possível fator pela procura da Faculdade da Terceira Idade para socialização com outras pessoas.

Quadro 3 - Condição de moradia dos inscritos na FTI.

\begin{tabular}{|c|c|c|}
\hline \multicolumn{3}{|c|}{ CONDIÇÃO DE MORADIA } \\
\hline Condição & Alunos & $\%$ \\
\hline Sozinho & 103 & $38,4 \%$ \\
\hline Com filhos & 57 & $21,4 \%$ \\
\hline Com netos & 4 & $1,5 \%$ \\
\hline Casal & 69 & $25,7 \%$ \\
\hline Casal c/ filhos & 25 & $9,3 \%$ \\
\hline Com parentes & 10 & $3,7 \%$ \\
\hline Outros & 0 & $0 \%$ \\
\hline Não informado & 0 & $0 \%$ \\
\hline TOTAL & 268 & $100 \%$ \\
\hline
\end{tabular}

Fonte: Faculdade da Terceira Idade Univap (2021).

A renda familiar dos inscritos na $\mathrm{FTI}$, segundo dados do quadro 4 , revelam a maior porcentagem de 35,8\% com renda acima de $\mathrm{R} \$ 3.000,00$. Tal renda é de um valor relevante, considerando o salário mínimo nominal no Brasil. Ademais, de acordo com o levantamento realizado pelo Serviço Social, essa renda é proveniente de aposentadoria, com uma porcentagem de $67 \%$ dos (as) inscritos (as).

Quadro 4 - Renda familiar dos inscritos na FTI.

\begin{tabular}{|c|c|c|c|c|c|c|c|}
\hline \multicolumn{7}{|c|}{ RENDA FAMILIAR } \\
\hline $\begin{array}{c}\text { Até } \\
\mathbf{2 5 0 , 0 0}\end{array}$ & $\begin{array}{c}\mathbf{2 5 1 , 0 0} \text { à } \\
\mathbf{5 0 0 , 0 0}\end{array}$ & $\begin{array}{c}\mathbf{5 0 1 , 0 0} \text { à } \\
\mathbf{1 0 0 0 , 0 0}\end{array}$ & $\begin{array}{c}\mathbf{1 0 0 1 , 0 0} \text { à } \\
\mathbf{2 0 0 0 , 0 0}\end{array}$ & $\begin{array}{c}\mathbf{2 0 0 1 , 0 0} \text { à } \\
\mathbf{3 0 0 0 , 0 0}\end{array}$ & $\begin{array}{c}\text { Acima de } \\
\mathbf{3 0 0 1 , 0 0}\end{array}$ & $\begin{array}{c}\text { Não } \\
\text { Informado }\end{array}$ & TOTAL \\
\hline 5 & 2 & 27 & 46 & 78 & 96 & 14 & 268 \\
\hline $1,9 \%$ & $0,7 \%$ & $10,1 \%$ & $17,2 \%$ & $29,1 \%$ & $35,8 \%$ & $5,2 \%$ & $100 \%$ \\
\hline \multicolumn{7}{|c|}{ Fonte: Faculdade da Terceira Idade Univap (2021). } \\
\hline
\end{tabular}

Conforme o quadro 5, o estado civil dos (as) inscritos (as), os dados que se 
sobressaem são as porcentagens de pessoas casadas e viúvas por serem as maiores, $35,8 \%$ e $32,5 \%$, respectivamente. No entanto, um dado interessante é a porcentagem de pessoas solteiras $(11,2 \%)$, no qual é possível relacionar este com a mesma questão da condição de moradia: a necessidade de relações com outras pessoas.

Quadro 5 - Estado civil dos inscritos na FTI.

\begin{tabular}{|c|c|c|c|c|c|c|c|}
\hline \multicolumn{7}{|c|}{ ESTADO CIVIL } \\
\hline Solteiro & Casado & Separado & $\begin{array}{c}\text { Separado } \\
\text { Jud. }\end{array}$ & Divorciado & Viúvo & $\begin{array}{c}\text { Não } \\
\text { Informado }\end{array}$ & TOTAL \\
\hline 30 & 96 & 9 & 1 & 36 & 87 & 9 & 268 \\
\hline $11,2 \%$ & $35,8 \%$ & $3,3 \%$ & $0,4 \%$ & $13,5 \%$ & $32,5 \%$ & $3,3 \%$ & $100 \%$ \\
\hline
\end{tabular}

Fonte: Faculdade da Terceira Idade Univap (2021).

Com relação ao nível de escolaridade, são poucos os (as) inscritos (as) que não completaram o ensino fundamental, apenas $4,5 \%$, enquanto $38,5 \%$ possuem ensino médio completo; e ainda, 30,2\% possuem ensino superior completo.

Quadro 6 - Escolaridade dos inscritos na FTI.

\begin{tabular}{|c|c|c|c|c|c|c|c|}
\hline \multicolumn{8}{|c|}{ ESCOLARIDADE } \\
\hline \multicolumn{2}{|c|}{$\begin{array}{c}\text { Ensino } \\
\text { Fundamental }\end{array}$} & \multicolumn{2}{|c|}{ Ensino Médio } & \multicolumn{2}{|c|}{ Ensino Superior } & \multirow[b]{2}{*}{$\begin{array}{c}\text { Não } \\
\text { Informado }\end{array}$} & \multirow[b]{2}{*}{ TOTAL } \\
\hline $\begin{array}{l}\text { Fund. } \\
\text { Comp. }\end{array}$ & $\begin{array}{c}\text { Fund. } \\
\text { Incomp. }\end{array}$ & $\begin{array}{l}\text { Médio } \\
\text { Comp. }\end{array}$ & \begin{tabular}{|c|} 
Médio \\
Incomp. \\
\end{tabular} & $\begin{array}{l}\text { Sup. } \\
\text { Comp. }\end{array}$ & $\begin{array}{c}\text { Sup. } \\
\text { Incomp. }\end{array}$ & & \\
\hline 34 & 12 & 103 & 9 & 81 & 22 & 7 & 268 \\
\hline $12,7 \%$ & $4,5 \%$ & $38,5 \%$ & $3,3 \%$ & $30,2 \%$ & $8,2 \%$ & $2,6 \%$ & $100 \%$ \\
\hline
\end{tabular}

Fonte: Faculdade da Terceira Idade Univap (2019).

No que diz respeito à região de moradia, o quadro 7 aponta que $25,5 \%$ dos (as) inscritos (as) são provenientes são da região central do município de São José dos Campos, fato este que se atrela quanto à localização da Faculdade da Terceira Idade, no centro da cidade. Outro ponto a ser destacado é a porcentagem de pessoas advindas de cidades próximas ao município (5,3\%), como Jacareí, Taubaté, Caçapava, Monteiro Lobato e até mesmo Guararema, no estado de São Paulo. Além de que, com relação ao tipo de moradia os dados coletados apontam que $78 \%$ possuem residência própria.

Quadro 7 - Região de moradia dos inscritos na FTI

\begin{tabular}{|c|c|c|c|c|c|c|c|c|}
\hline Norte & Centro & Leste & Sul & Sudeste & Oeste & $\begin{array}{c}\text { Outras } \\
\text { Cidades }\end{array}$ & $\begin{array}{c}\text { Não } \\
\text { Informado }\end{array}$ & Total \\
\hline 25 & 69 & 55 & 54 & 7 & 38 & 14 & 7 & 268 \\
\hline $9,3 \%$ & $25,5 \%$ & $20,5 \%$ & $20 \%$ & $2,6 \%$ & $14,2 \%$ & $5,3 \%$ & $2,6 \%$ & $100 \%$ \\
\hline \multicolumn{7}{|c|}{ Fonte: Faculdade da Terceira Idade Univap (2019). }
\end{tabular}

À vista disso, analisando o perfil socioeconômico elaborado pelo curso de Serviço Social da UNIVAP, é revelado que a maior composição do espaço ocorre por mulheres entre 58 a 71 anos, ou seja, pessoas entrando e já na fase em que o envelhecimento biológico se de destaca no sujeito. Além disso, em sua maioria são pessoas aposentadas e que vivem em uma condição de moradia e estado civil propícios a buscarem outras alternativas para alcançarem um abrangimento de 
convívio social, de fato, consolidados de relações e produções sociais - como ocorre na Faculdade da Terceira Idade, através das aulas no CEAC, CEATI e oficinas de expressão sensível.

Ao continuar a análise, nota-se que estas pessoas - em sua maioria, pessoas idosas - possuem uma boa condição de vida, pois, grande parte dos (as) inscritos (as) possuem uma renda mensal acima de três mil reais - mesmo esta não sendo considerada ideal para se viver no país, segundo a síntese "Salário mínimo nominal e necessário" (DIEESE, 2021), do Departamento Intersindical de Estatística e Estudos Socioeconômicos (Dieese), em que no mês de janeiro de 2021 o salário mínimo necessário deveria ser de $\mathrm{R} \$ 5.495,52$-, residência própria e vivem em uma das regiões mais valorizadas do município, o centro da cidade.

Outro indicador que evidencia aspectos do modo de vida dos (as) inscritos (as) é o nível de escolaridade, sendo que 39\% possuem ensino médio completo e $30 \%$ completaram até mesmo a educação em nível superior.

Portanto, o perfil socioeconômico analisado reflete na realidade social brasileira: o acesso à espaços de educação continuada ainda é um desafio a ser alcançado na totalidade do país. Isto, devido às desigualdades sociais existentes e perpassadas nas relações entre os indivíduos sociais, caracterizadas como dimensões da vida social.

\section{CONCLUSÃO}

Infere-se a importância do estudo social - o perfil socioeconômico - neste recorte da população que frequenta a Faculdade da Terceira Idade UNIVAP, a fim de levantar questões sobre o envelhecimento para a compreensão das demandas advindas das camadas societárias - como a procura por atualização cultural, entretenimento, lazer e troca de conhecimentos em espaços de educação informal -, as quais compõem e realizam a dinamicidade do campo social.

Posto isto, e retomando a questão do aumento da longevidade apresentado na seção quatro, Dados da longevidade no Brasil e no munícipio de São José dos Campos/SP, e dos aspectos dos alunos e alunas apresentados no perfil socioeconômico desenvolvido pelo Serviço Social da Universidade do Vale do Paraíba; estudos sobre o envelhecimento apontam que os avanços da tecnologia, principalmente os que se referem à saúde, à prática de exercícios físicos e alimentação saudável são fatores estreitamente co-relacionados com o aumento da longevidade humana.

Logo, segundo os dados é notório que a população idosa feminina se sobrepõe à masculina, o que de acordo com Patrício et al. (2008), possui relação ao fato de que as mulheres que têm filhos após os 40 anos demonstram maior chance de viver. A explicação disse fenômeno se dá pelo sistema reprodutor feminino, o qual nessas condições tende a ter um funcionamento melhor, e consequentemente, seus outros órgãos do corpo - fazendo com que o processo de envelhecimento seja mais lento. Além disso, Patrício et al. (2008) também menciona tendo como base trabalhos realizados com a população longeva, que os idosos que mantém bom funcionamento psicológico, com atividades positivas para a mente humana, vivem mais se comparados aos idosos que mantém em isolamento, com falta de atividade intelectual.

Sendo assim, a Faculdade da Terceira Idade UNIVAP colabora de modo efetivo para com seu público atendido: mulheres idosas com uma boa qualidade de vida, em sua maioria; estimulando a participação dessas alunas e dos alunos como agentes habilitados para ações com a família e meio social, na defesa dos direitos da 
população idosa e permitindo acesso à educação continuada bem como propiciando condições para o desenvolvimento do indivíduo e sua integração junto à comunidade, reconhecendo seu potencial de contribuição para a sociedade e seus direitos enquanto cidadão.

No cotidiano de prática e supervisão de estágio em Serviço Social na FTI, por meio da observação participante no local e do perfil socioeconômico apresentado, com base nos fatores associados à longevidade, compreende-se que grande parte dos que frequentam o espaço analisado - as mulheres - reconhecem que a Faculdade da Terceira Idade coopera para com o convívio social. Pois, através de relatos e conversas em grupo na sala de aula as alunas discorrem e demonstram à extramuros que se desenvolveram e expandiram círculos de amizade após frequentar o local. Ademais, outra observação que se destaca é acerca da atenção dada por parte dos profissionais inseridos no espaço aos idosos, sendo o acolhimento e o atendimento, os quais se refletem na permanência do sujeito e procura por parte de idosos terceiros - estes, que ainda não adentraram à FTI.

Portanto, faz-se importante investir no desenvolvimento social, no qual se considera que a sociabilidade é inerente à condição humana, levando o sujeito social a melhor compreender-se e compreender o mundo contemporâneo em todas as suas implicações e totalidade das questões sociais postas à realidade, assim como o ritmo das transformações do campo social, entre elas o fenômeno do envelhecimento, e as relações entre pessoas. Enquanto que para o Serviço Social, responsável pela análise e elaboração do perfil socioeconômico dos alunos e alunas, tendo em vista os princípios éticos do Código de Ética Profissional do (a) Assistente Social:

III. Ampliação e consolidação da cidadania, considerada tarefa primordial de toda sociedade, com vistas à garantia dos direitos civis sociais e políticos das classes trabalhadoras;

V. Posicionamento em favor da equidade e justiça social, que assegure universalidade de acesso aos bens e serviços relativos aos programas e políticas sociais, bem como sua gestão democrática;

IX. Articulação com os movimentos de outras categorias profissionais que partilhem dos princípios desde Código e com a luta geral dos (as) trabalhadores (as);

X. Compromisso com a qualidade dos serviços prestados à população e com o aprimoramento intelectual, na perspectiva da competência profissional (CFESS, 2012).

Dessa forma, levando em consideração o cotidiano da prática e supervisão na Faculdade da Terceira Idade em relação a formação profissional em Serviço Social, entende-se a necessidade do estudo social acerca do perfil socioeconômico dos inscritos na instituição, a fim de viabilizar novos conteúdos que ampliem o conhecimento acadêmico ao profissional, em atenção às reais demandas postas na realidade social do espaço analisado correlacionando-o com a totalidade histórica da sociedade, e em direção ao projeto ético-político da profissão, de maneira a efetivar direitos e consolidar a cidadania à todos e todas do campo social.

Todavia, ao mesmo tempo é necessário conhecer e compreender as expressões da questão social posta à realidade brasileira, reconhecendo as tensões, relações de força advindas das produções entre as classes e contradições do sistema capitalista frente ao neoliberalismo, em que as desigualdades sociais são naturalizadas à altos níveis, impactando diretamente na vida da população e em seus direitos, no que diz respeito à dignidade humana e ao acesso à bens e serviços dispostos no meio social. 
Em vista disso, compreender as múltiplas expressões e significados sobre o envelhecimento pelas alunas da Faculdade da Terceira Idade UNIVAP, entendendo como a mulher é percebida na sociedade com relação a questão do gênero e a velhice - fenômenos estes que estão postos à realidade social e que têm sido cada vez mais discutidos pela ciência devido ao aumento mundialmente da longevidade humana, especialmente da longevidade feminina como observado nos dados nacionais e do perfil socioeconômico da FTI apresentados -, é realizar um processo de reflexão intergeracional - entre as idosas e estudantes em processo de formação da universidade -, em que se é possível discutir direitos e deveres, adentrar em pautas gerais do campo social e refletir sobre o processo de envelhecimento e desenvolvimento da comunidade. Como, por exemplo, as atividades virtuais realizadas pelas redes sociais da FTI e UNIVAP durante a pandemia do Covid-19, em que estas idosas participam ativamente e socialmente, com perguntas, comentários sugestões de temas e divulgação a familiares e comunidade; com esforço para que todos aos arredores também tenham acesso à atualização cultural e à educação continuada.

Logo, entende-se a importância de promover o bem-estar da pessoa idosa e a participação da sociedade civil para o convívio social, de fato, efetivo; com vistas à garantia de direitos, e em consonância com o Estatuto do Idoso (BRASIL, 2003) e com os princípios fundamentais do Código de Ética profissional do (a) Assistente Social, no que diz respeito à materialização da cidadania, justiça social, universalidade de acesso aos bens e serviços, articulação multiprofissional e transdisciplinar, emancipação dos indivíduos sociais e o compromisso com a qualidade de serviços prestados à população. Por fim, em relação de forma interligada a UNIVAP e FTI desenvolvem de modo interdisciplinar e interdepartamental o tratamento da questão da longevidade e envelhecimento, enquanto campo de atuação, ensino e pesquisa, estes que compõem o tripé de uma Instituição de Ensino Superior Comunitária.

Assim, a FTI oferece campos de atuação e estágio para estudantes em formação profissional da UNIVAP, no cotidiano da prática e com estímulos em pesquisas relacionadas à temática da terceira idade de modo a materializar o ensino de maneira efetiva para o mercado de trabalho. Ademais, tal relação consolida uma das finalidades da Universidade do Vale do Paraíba, no sentido de colocar a sua competência à disposição da comunidade, promovendo a extensão e a participação acadêmica-sociedade civil, com vistas à difusão dos resultados de criações culturais e pesquisas cientificas e tecnológicas.

\section{REFERÊNCIAS}

ATLAS BRASIL. [Perfil São José dos Campos, SP]. 2017. Disponível em: http://www.atlasbrasil.org.br/perfil/municipio/354990\#sec-demografia. Acesso em: 23 fev. 2021.

BEAUVOIR, S. A velhice: a realidade incômoda. São Paulo: Difusão Europeia do Livro, 1970. v. 1.

BRASIL. Constituição (1988). Constituição da República Federativa do Brasil. Brasília, DF: Senado Federal; Centro Gráfico, 1988.

BRASIL. Lei $\mathrm{n}^{\circ} 10.741$, de $1^{\circ}$ de outubro de 2003. Dispõe sobre o Estatuto do Idoso 
e dá outras providências. Diário Oficial [da] República Federativa do Brasil, Brasília, DF, 03 out. 2003, p.1.

CFESS. Código de ética do/a assistente social. Lei 8.662/93 de regulamentação da profissão. 10a . ed. Brasília, DF: Conselho Federal de Serviço Social, 2012. Disponível em: http://www.cfess.org.br/arquivos/CEP_CFESS-SITE.pdf. Acesso em: 25 fev. 2021.

DEBERT, G. G. Gênero Envelhecimento. Revista Estudos Feministas, Florianópolis, v. 2, n. 3, p. 33-51, jan. 1994. Disponível em:

https://periodicos.ufsc.br/index.php/ref/article/view/16288. Acesso em: 25 fev. 2021.

DIEESE - Departamento Intersindical de Estatísticas e Estudos Socioeconômicos.

Salário mínimo nominal e necessário, 2021. Disponível em:

https://www.dieese.org.br/analisecestabasica/salarioMinimo.html. Acesso em: 23 fev. 2021.

ESTATÍSTICAS SOCIAIS. Expectativa de vida dos brasileiros aumenta para 76,3 anos em 2018. Censo 2021, 28 nov. 2019. Disponível em:

https://censo2021.ibge.gov.br/2012-agencia-de-noticias/noticias/26103-expectativade-vida-dos-brasileiros-aumenta-para-76-3-anos-em-2018.html . Acesso em: 23 fev. 2021.

FACULDADE DA TERCEIRA IDADE UNIVAP. Perfil socioeconômico do $\mathbf{2}^{\circ}$ semestre de 2019. São José dos Campos/SP: Universidade do Vale do Paraíba, 2021. (Não publicado).

FACULDADE DA TERCEIRA IDADE UNIVAP. Resumo Interno do Projeto, 2020. São José dos Campos, SP: Universidade do Vale do Paraíba, 2021. (Não publicado).

FIGUEIREDO, M. L. F. et al. As diferenças de gênero na velhice. Revista brasileira de enfermagem, Brasília, v. 60, n. 4, p. 422-427, ago. 2007. Disponível em: http://scielo.br/scielo.php?script=sci arttext\&pid=S003471672007000400012\&lng=en\&nrm=iso. Acesso em: 24 fev. 2021.

GIL, R. L. Tipos de pesquisa. 2009. Disponível em:

https://wp.ufpel.edu.br/ecb/files/2009/09/Tipos-de-Pesquisa.pdf. Acesso em: 18 ago. 2020.

GOOGLE IMAGENS. [Município de São José dos Campos, SP]. [S.I.: s.n.], 2021.

GUEDES, D. W. O. Educação continuada e projeto de vida de pessoas idosas. 2006. 122 f. Dissertação (Mestrado em Gerontologia) - Pontifícia Universidade Católica de São Paulo, São Paulo, 2006. Disponível em:

https://tede2.pucsp.br/handle/handle/12493 Acesso em: 27 fev. 2021.

IBGE - INSTITUTO BRASILEIRO DE GEOGRAFIA E ESTATISTICA.

Características gerais dos domicílios e dos moradores: 2017. Rio de Janeiro:

IBGE, 2018. Disponível em:

https://biblioteca.ibge.gov.br/index.php/bibliotecacatalogo?view=detalhes\&id=210156 
6. Acesso em: 28 fev. 2021.

IBGE EDUCA. Pirâmide etária. 2019. Disponível em:

https://educa.ibge.gov.br/jovens/conheca-o-brasil/populacao/18318-piramideetaria.html. Acesso em: 23 fev. 2021.

IMPERATORI, T. K. A compreensão de cuidadores sobre o cuidado de familiares idosos com a doença de Alzheimer. 2007. 59 p. Trabalho de conclusão de Curso (Graduação em Serviço Social). Universidade de Brasília, Brasília, DF, 2007. Disponível em:

https://bdm.unb.br/bitstream/10483/716/1/2007 ThaisImperatori.pdf. Acesso em: 28 fev. 2021.

MADEIRA, Z.; GOMES, D. D. O. Persistentes desigualdades raciais e resistências negras no Brasil contemporâneo. Serviço social e sociedade, São Paulo, n. 133, p. 463-479, set./dez. 2018. Disponível em: http://www.scielo.br/pdf/sssoc/n133/01016628-sssoc-133-0463.pdf . Acesso em: 16 mai. 2021.

MOTTA, A. B. As dimensões de gênero e classe social na análise do envelhecimento. Cadernos Pagu, Campinas, n. 13, p. 191-221, set/1999. Disponível em:

https://periodicos.sbu.unicamp.br/ojs/index.php/cadpagu/article/view/8635327/3129. Acesso em: 16 maio 2021.

PATRÍCIO, K. P. et al. O segredo da longevidade segundo as percepções dos próprios longevos. Ciência \& Saúde Coletiva, Rio de Janeiro, v.13, n. 4, p.11891198, ago. 2008. Disponível em:

https://www.scielosp.org/article/csc/2008.v13n4/1189-1198/. Acesso em: 24 fev. 2021.

SÃO JOSÉ DOS CAMPOS, Prefeitura. Secretaria de Planejamento Urbano. São José em dados 2016: informações sobre a cidade de São José dos Campos. São José dos Campos, SP: Prefeitura Municipal de São José dos Campos, 2012. 132 p.

SEADE - Fundação Sistema Estadual de Análise de Dados. Em 2050, a população idosa irá triplicar no Estado de São Paulo. 2017. Disponível em:

https://www.seade.gov.br/em-2050-populacao-idosa-ira-triplicar-no-estado-de-saopaulo/. Acesso em: 8 jul. 2020.

SEADE - Fundação Sistema Estadual de Análise de Dados. Vive-se mais e melhor. 2020. Disponível em: https://www.seade.gov.br/vive-se-mais-e-melhorl. Acesso em: 23 fev. 2021. 